\title{
Bio-Analytical Method Development for Estimation of Levofloxacin: Application in Estimation of Drug in Nano-formulations and Pharmacokinetic Studies
}

\author{
Priyanka Maurya', Abhiram Kumar², Samipta Singh'1, Raquibun Nisha1, Ravi Raj Pal', \\ Manish Kumar Chourasia ${ }^{2, *}$, Shubhini Awasthi Saraf ${ }^{1, *}$
}

${ }^{1}$ Department of Pharmaceutical Sciences, Babasaheb Bhimrao Ambedkar University (A Central University) Vidya Vihar, Lucknow, Uttar Pradesh, INDIA.

2Department of Pharmaceutics and Pharmacokinetics, CSIR-Central Drug Research Institute Sector 10, Lucknow, Uttar Pradesh, INDIA.

*Equal Contribution

\begin{abstract}
Aim/Background: Levofloxacin is a safe antibiotic for various inflammatory disorders and a rapid analytical method for various samples reduces the estimation time as well as injects efficiency in the system. The developed method uses minimal solvents with least preparation time also helps in reducing the errors generated by the analyst during processing. Materials and methods: RP-HPLC method was developed for estimation of levofloxacin using Box Behnken Design. The PDA detector was set at $295 \mathrm{~nm}$ with a run time of 6 mins. The samples were run at binary gradient mode with $35 \%$ phase B. The mobile phase consisted of acetate buffer, acetonitrile and methanol. Linearity was established for pure drug as well as spiked plasma samples. Drug extraction from plasma samples was done by liquid-liquid extraction using acetonitrile and methanol. Results: The developed method has a retention time of $3.1 \pm 0.41$ mins and is validated as per ICHQ2R1 guidelines. The standard curve indicates high correlation with a $R^{2}$ value of 0.9999 . The robustness $(R S D<2)$ and system suitability studies indicate that it is a stable method with high specificity as determined with different samples. The LOD and $\mathrm{LOQ}$ were found to be $0.08 \mathrm{ppm}$ and $0.25 \mathrm{ppm}$ respectively indicating estimations of samples with a low drug content. Conclusion: A rapid, robust, selective, simple and sensitive method was developed and validated for quick estimation of levofloxacin in different sample. The significant reduction in retention time obtained by the developed method proves its efficiency in tapping the mobile phase costs as well as expediting the analytical process. The DOE optimised method is suitable for rapid estimation of levofloxacin in plasma as well as nanoformulations.
\end{abstract}

Key words: Bioanalytical method, Robustness, Specificity, Stability, ICHQ2R1.

\section{INTRODUCTION}

Levofloxacin hemihydrate (LH) a fluoroquinolone antibiotic effectively used to treat tubercular infections. It is the most effective broad spectrum antibiotic for gram positive and gram negative bacterial infections. $\mathrm{LH}$ is a Biopharmaceutical Classification System (BCS) class 1 drug with a 6-8 hr elimination half- life. Extensive literature review showed us a wide array of estimation methods of levofloxacin. Several of these were tried to estimate the drug content in our hybrid poly D,L-lactic-coglycolic acid (PLGA) nanoformulations as well as for pharmacokinetic studies to least efficiency. LH is a well-studied drug Therefore, while developing the reversed phase-High performance liquid chromatography (RP-HPLC) method we came across some easy methods, some troublesome methods with advanced detection techniques and gradient elution methods. The one thing that remained
Submission Date: 02-02-2021; Revision Date: 12-04-2021; Accepted Date: 23-09-2021

DOI: 10.5530/ijper.55.3s.189 Correspondence: Prof. Shubhini A Saraf, Shubhini A Saraf Department of Pharmaceutical Sciences, Babasaheb Bhimrao Ambedkar University (A Central University) Vidya Vihar, Lucknow-226025, Uttar Pradesh, INDIA. Phone: +91 9415488410, Email - shubhini.saraf@gmail. com

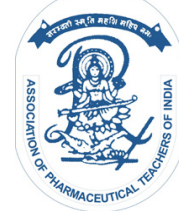

www.ijper.org 
consistent throughout were the gradual improvements in estimation methods. The study is aimed to develop HPLC method that can effectively estimate LH in plasma, nanoformulations and conventional formulations as well as in cytology studies. The reduced run time and lesser chemicals required in mobile phase preparation will lead to reduced instrumental, method and personal errors due to lesser variables.

\section{MATERIALS AND METHODS}

Method development and optimization was done using design of experiments. Box Behnken design was selected as it provided greater flexibility in selection of variables and reduces the number of experimental runs. BBD helps in optimising the experimental parameters without increasing the runs and maintaining the rationality of the design

\section{Chemicals}

Levofloxacin was a generous gift from Sun Pharma. Acetonitrile, Methanol, Formic acid, orthophosphoric acid and ammonium acetate were purchased from Merck. Milli Q water was used throughout the study. All chemicals and reagents used in HPLC were of chromatographic grade.

\section{Method Development}

A box-behnken design was chosen to develop the process parameters for estimation of levofloxacin hemihydrate. 3 factors at 3 levels with 6 centre points were selected for the study. The design was selected as it reduces the number of runs of a full factorial without compromising on the effectiveness of the factors. The factors and levels selected for optimization were $\mathrm{pH}$ $(\mathrm{pH} 4-5)$, column oven temp $\left(30-40^{\circ} \mathrm{C}\right)$ and flow rate (0.8-1.2). 18 experimental runs were performed randomly and HPLC areas, Number of theoretical plates (NTP), tailing factor and retention time were the dependant factors for the study. Experimental design matrix and the Analysis of variance (ANOVA) results obtained are tabulated in Table 1 and 2.

\section{Chromatographic Conditions}

The analysis was carried out on Shimadzu (Shimadzu corporation, Japan) equipped with a PDA detector SPD M20A with a $\mathrm{D}_{2}$ lamp. Chromatograms were recorded by LC solutions software. Analysis was performed on Waters X Bridge $\mathrm{C}_{18}$ column (250X4.6mm, $\left.5 \mu \mathrm{m}\right)$. Auto sampler SIL 20AC was used for sample injection with a needle stroke of $52 \mathrm{~mm}$ at a sampling rate of $15 \mu \mathrm{l} / \mathrm{sec}$. Injection volume was set at $25 \mu \mathrm{l}$ and detection wavelength at $295 \mathrm{~nm}$. Oven was maintained at $30^{\circ} \mathrm{C}$ and samples were maintained at ambient temperature. Mobile phase selected for separation of components was a mixture of $100 \mathrm{mM}$ ammonium acetate buffer and 1:1 mix of acetonitrile and methanol. Binary gradient mode was utilized with $35 \%$ phase $B$ at an overall flow rate of $0.93 \mathrm{ml} / \mathrm{min}$ for $6 \mathrm{~min}$ run time.

\section{Preparation of mobile phase}

Mobile Phase A- accurately weighed amount (3.854 g) of ammonium acetate (Mettler Toledo ME 204 digital balance) was transferred to a $500 \mathrm{ml}$ Borosil volumetric flask, dissolved ammonium acetate in $0.1 \%$ formic acid containing Milli Q water. Diluted orthophosphoric acid was used to maintain the $\mathrm{pH}$ using Hanna $\mathrm{pH}$ meter. Mobile phase was clarified through $0.22 \mu \mathrm{m}$ membrane filter and degassed in a sonicator bath. Mobile Phase- B: a mixture of 1:1 acetonitrile and methanol respectively were used. Preparation of Diluents-1:1 Acetonitrile and methanol were used as diluents for preparation of samples which is hereafter referred to as diluent.

\section{Preparation of Stock solutions}

The standard stock solution of Levofloxacin (1000 ppm) was prepared. $10 \mathrm{mg}$ of accurately weighed Levofloxacin was transferred to $10 \mathrm{ml}$ volumetric flask and $5 \mathrm{ml}$ of diluent was poured in it, sonicated the drug solution and made up the volume with diluent. The stock solution was transferred to $5 \mathrm{ml}$ volumetric flasks and half fold diluted concentrations of 128 parts per million (ppm) to $0.5 \mathrm{ppm}$ were prepared for linearity studies. Estimation of limit of detection (LOD) and limit of quantification (LOQ) considered 5-point calibration curve from $0.5 \mathrm{ppm}$ to $8 \mathrm{ppm}$.

\section{Sample preparation for spiked plasma calibration curve.}

Drug free plasma was spiked with a stock solution of levofloxacin to obtain a concentration of $1000 \mathrm{ppm}$. This mixture was deproteinated in presence of acetonitrile and methanol. It was vortexed for 5 mins and centrifuged at $13500 \mathrm{rpm}$ for 30 mins. The clear supernatant obtained was separated and dried in a nitrogen evaporator. The dried product was reconstituted using the diluent to obtain a concentration of $512 \mathrm{ppm}$. The prepared samples were filtered through $0.22 \mu \mathrm{m}$ nylon syringe filters. The suitable volume of the resulting solution was transferred and diluted to $128 \mathrm{ppm}$. Nine different concentrations of plasma standard samples were prepared by half-fold dilution technique i.e., $128 \mathrm{ppm}, 64 \mathrm{ppm}, 32 \mathrm{ppm}, 16 \mathrm{ppm}$, 8 ppm, 4 ppm, 2 ppm, 1 ppm and 0.5 ppm for establishment of linearity and range. Similarly, five different 
Table 1: Experimental design matrix and optimisation parameters.

\begin{tabular}{|c|c|c|c|}
\hline Standard & $\begin{array}{c}\text { Mobile phase } \\
\mathbf{p H}\end{array}$ & $\begin{array}{c}\text { Flow rate } \\
(\mathbf{m l} / \mathbf{m i n})\end{array}$ & $\begin{array}{c}\text { Column Oven } \\
\text { Temp }\left({ }^{\circ} \mathbf{C}\right)\end{array}$ \\
\hline 1. & 4.00 & 0.80 & 35.00 \\
\hline 2. & 5.00 & 0.80 & 35.00 \\
\hline 3. & 4.00 & 1.20 & 35.00 \\
\hline 4. & 5.00 & 1.20 & 35.00 \\
\hline 5. & 4.00 & 1.00 & 30.00 \\
\hline 6. & 5.00 & 1.00 & 30.00 \\
\hline 7. & 4.00 & 1.00 & 40.00 \\
\hline 8. & 5.00 & 1.00 & 40.00 \\
\hline 9. & 4.50 & 0.80 & 30.00 \\
\hline 10. & 4.50 & 1.20 & 30.00 \\
\hline 11. & 4.50 & 0.80 & 40.00 \\
\hline 12. & 4.50 & 1.20 & 40.00 \\
\hline 13. & 4.50 & 1.00 & 35.00 \\
\hline 14. & 4.50 & 1.00 & 35.00 \\
\hline 15. & 4.50 & 1.00 & 35.00 \\
\hline 16. & 4.50 & 1.00 & 35.00 \\
\hline 17. & 4.50 & 1.00 & 35.00 \\
\hline 18. & 4.50 & 1.00 & 35.00 \\
\hline $\begin{array}{c}\text { Optimisation } \\
\text { parameters }\end{array}$ & Goal & Lower limit & Upper limit \\
\hline HPLC Area & is in range & 2500000 & 3900000 \\
\hline USP (NTP) & is in range & 4000 & 5300 \\
\hline Tailing & is in range & 0.5 & 1 \\
\hline R.T & is in range & 3 & 3.5 \\
\hline & & & \\
\hline
\end{tabular}

concentrations range from $0.5 \mathrm{ppm}$ to $8 \mathrm{ppm}$ were considered for LOD and LOQ estimation by signal to noise technique.

\section{Preparation of sample for pharmacokinetic study}

Wistar rats procured from Indian Veterinary Research Institute (IVRI), Bareilly were divided into groups as per the approved protocol. The animals were fasted overnight and were given water ad libitum. The animals were administered with single oral dose of developed formulation and blood samples were collected in heparinised tubes through retro-orbital route under anaesthesia. Levofloxacin was extracted from plasma sample by using liquid-liquid extraction method. The tubes were centrifuged at $13500 \mathrm{rpm}$ for $10 \mathrm{~min}$ and plasma was separated. The plasma samples were immediately put in $-20^{\circ} \mathrm{C}$ refrigerator. $100 \mu$ samples were taken out from each tube for analysis and mixed with a diluent. Deproteination was followed by centrifugation and separation of clear supernatant. The clear supernatant was dried and reconstituted with diluent. The resulting samples were filtered through $0.22 \mu \mathrm{m}$ nylon filter prior to injecting in HPLC. The observed values were calculated through the following parameters obtained by spiked plasma calibration curve. The slope was 129255 with an intercept of -94992 . The approval number for pharmacokinetic studies is BBDNIIT/ IAEC/2019/01.

\section{Preparation of nanoformulation}

Soya lecithin, PLGA and levofloxacin were dissolved in dichloromethane in individual beakers. Lipidic and polymeric solutions were added to the aqueous phase containing poly vinyl alcohol under continuous stirring followed by sonication. The mixture was stirred for $24 \mathrm{~h}$ followed by centrifugation at $10000 \mathrm{rpm}$ for $30 \mathrm{~min}$. The final product pellet was lyophilized and subjected to drug content estimation.

\section{Method Validation}

In house method validation for the current method was carried as per ICH Q2R1 guidelines. Validation was done through linearity, system suitability, and limit of quantification, limit of detection, range, accuracy, recovery, precision, robustness, solution stability, specificity and ruggedness

\section{Linearity}

Linearity is the ability within a specific range to obtain areas proportional to the concentration of the analyse. Working solutions were prepared from 1000ppm stock solution stored at $-20^{\circ} \mathrm{C}$. Suitable dilutions were prepared in triplicate for $128 \mathrm{ppm}$ to $1 \mathrm{ppm}$. Least square linear regression equation was applied to the average area obtained from the study versus the concentration in ppm. Correlation, slope, intercept and $R^{2}$ values were obtained from it.

\section{Spectrum Scan and System Suitability}

System suitability studies are carried out to ensure the reproducibility and better resolution of the peaks each time the analysis is carried out. System suitability studies were done by simultaneously injecting 6 shots of similar concentrations and assessing suitability by comparing the observed HPLC area, number of theoretical plates and tailing factor.

\section{Precision}

Method precision was done by injecting 6 test solutions. Intermediate precision was done by a different analyst on different days under same experimental conditions. Standard deviation and overall relative standard deviation (RSD) were estimated. 


\section{Accuracy and recovery}

Accuracy of the method is ascertained by the recovery samples. The accuracy of the method was carried out by determining the recovery at three levels in triplicate 50\% (32ppm), 100\% (64ppm) and 150\% (96ppm).

\section{Robustness}

It is determined by making deliberate changes to the method parameters leading to reliable analytical results. Changes were made with reference to mobile phase composition, column oven temperature and flow rate. It was estimated by running 6 replicates at a concentration of $64 \mathrm{ppm}$.

\section{Solution Stability}

As part of robustness of the method and stability check of the solution, a solution stability test was performed by placing a $64 \mathrm{ppm}$ standard solution in tightly closed volumetric flasks at room temperature and under refrigeration. They were analysed at $4 \mathrm{hr}, 12 \mathrm{hr}$ and $24 \mathrm{hr}$.

\section{Peak Purity}

It is carried out for confirmatory studies to prove that the analyte peak in chromatogram is not corresponding to one or more similar components. The peak purity for the current study was determined at $32 \mathrm{ppm}$.

\section{RESULTS AND DISCUSSION}

The main target of the present investigation was to develop a method which can easily and specifically separate and quantitate LH from nanoformulations, plasma solutions, marketed formulations and cytology studies. To achieve the set goal, Box Behnken Design (BBD) was chosen due to its capacity to incorporate more variables with a lesser number of runs and better design resolution. BBD is an experimental design for response surface methodology. The design is fit to be used for quadratic models and gives better results in surface plots. Design Expert 11.1.2.0 was utilised for BBD. The assumptions putative to method development were

- Less use of organic solvents to minimise cost

- Difference between the pKa values of solvent and LH

- Run time should be less than 10 mins with low retention time.

- Tailing factor remains less than 1.5.

- Maximising the number of theoretical plates

The factors selected and results obtained for BBD are enumerated in Table 1 and 2. The study of ANOVA for the different dependent variables showed up a quadratic model with significant fit for all the factors and non-significance of lack of fit. The $R^{2}$ value for all the factors approached unity. Column oven temperature (C) played the insignificant role while mobile phase $\mathrm{pH}$ (A) and flow rate (B) were found as factors with significance with high $F$ values. Mobile phase $\mathrm{pH}$ had insignificant effect $(p=0.0512)$ on retention time (RT), whereas flow rate had insignificant effect $(p=0.1772)$ on tailing. Tailing was significantly affected by mobile phase $\mathrm{pH}\left(p=0.013^{*}\right)$ and by the product of BC $\left(p=0.0054^{*}\right)$. $\mathrm{A}^{2}$ affected HPLC Area and NTP $(p=$ $0.0108^{*}$ and $0.0038^{*}$, respectively). $\mathrm{B}^{2}$ affected tailing and RT with p values of $0.0155^{*}$ and $0.0012^{*}$, respectively. Mobile phase $\mathrm{pH}$ significantly affected HPLC area and USP NTP with $p$ values of $<0.0001^{*}$ and < $0.0001 \%$ respectively. Flow rate affects HPLC area, USP (NTP) and retention time significantly with $\mathrm{p}$ values of $0.0003 *,<0.0001 \%$ and $<0.0001 *$ respectively. Based on the assumption made during method development numerical and graphical optimisations were done and solutions with high desirability values were run for confirmation of point prediction. The resulting desirability cube and overlay plot is given in Figure 1. The equations for determination of different factors are enlisted below
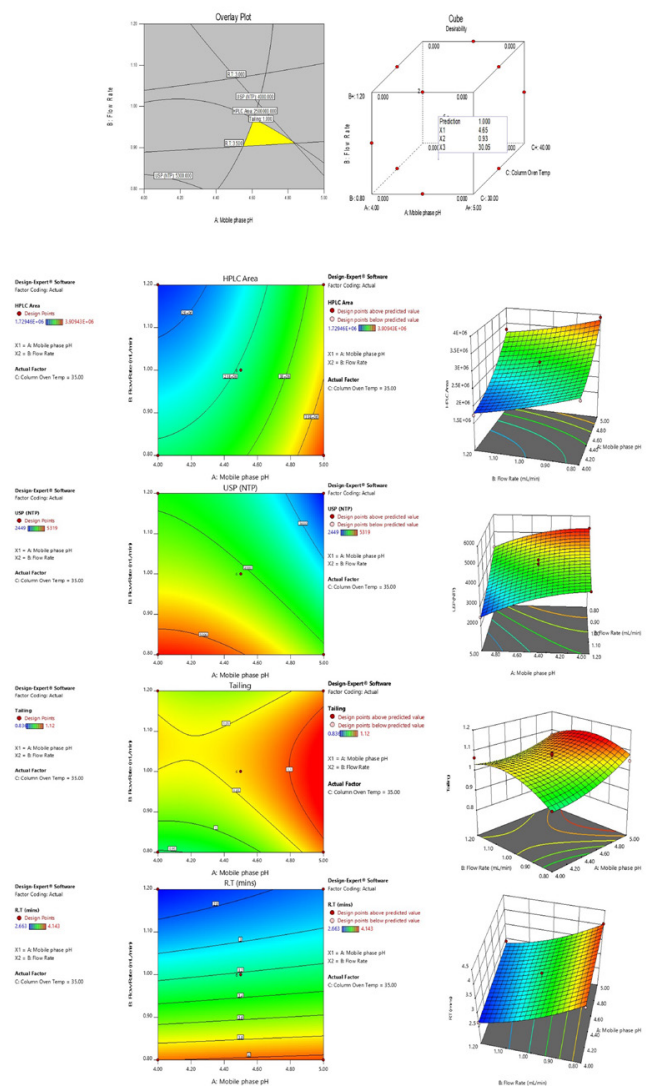

Figure 1: Desirability cube, overlay plot, 2D and 3D plot. 


\begin{tabular}{|c|c|c|c|c|c|c|c|c|c|}
\hline \multirow[b]{2}{*}{ Source } & \multirow[b]{2}{*}{ Df } & \multicolumn{2}{|c|}{ HPLC Area } & \multicolumn{2}{|c|}{ USP (NTP) } & \multicolumn{2}{|c|}{ Tailing } & \multicolumn{2}{|c|}{ Retention time } \\
\hline & & $\begin{array}{c}\mathrm{F} \\
\text { Value }\end{array}$ & $\begin{array}{l}\text { p-value } \\
\text { Prob > F }\end{array}$ & $\begin{array}{c}\mathrm{F} \\
\text { Value }\end{array}$ & $\begin{array}{l}\text { p-value } \\
\text { Prob }>F\end{array}$ & $\begin{array}{c}F \\
\text { Value }\end{array}$ & $\begin{array}{c}\text { p-value } \\
\text { Prob }>\text { F }\end{array}$ & $\begin{array}{c}\mathrm{F} \\
\text { Value }\end{array}$ & $\begin{array}{c}\text { p-value } \\
\text { Prob }>F\end{array}$ \\
\hline Model & 9 & 20.15 & $0.0001^{*}$ & 41.46 & $<0.0001^{*}$ & 5.14 & $0.0154^{*}$ & 64.97 & $<0.0001^{*}$ \\
\hline $\begin{array}{l}\text { A-Mobile } \\
\text { phase } \mathrm{pH}\end{array}$ & 1 & 126.18 & $<0.0001^{*}$ & 144.15 & $<0.0001^{*}$ & 10.10 & $0.0130^{*}$ & 5.25 & 0.0512 \\
\hline B-Flow Rate & 1 & 35.90 & $0.0003^{*}$ & 204.96 & $<0.0001^{*}$ & 2.19 & 0.1772 & 551.56 & $<0.0001^{*}$ \\
\hline $\begin{array}{l}\text { C-Column } \\
\text { Oven Temp }\end{array}$ & 1 & 0.81 & 0.3948 & 0.33 & 0.5795 & 1.00 & 0.3474 & 0.54 & 0.4837 \\
\hline$A B$ & 1 & 0.29 & 0.6069 & 0.95 & 0.3572 & 1.24 & 0.2974 & 0.60 & 0.4603 \\
\hline$A C$ & 1 & 0.31 & 0.5939 & 0.84 & 0.3870 & 0.026 & 0.8761 & 0.0004 & 0.9848 \\
\hline $\mathrm{BC}$ & 1 & 2.78 & 0.1341 & 0.67 & 0.4377 & 14.27 & $0.0054^{*}$ & 2.39 & 0.1610 \\
\hline$A^{2}$ & 1 & 10.92 & $0.0108^{*}$ & 16.17 & $0.0038^{*}$ & 2.78 & 0.1338 & 0.0038 & 0.9522 \\
\hline $\mathrm{B}^{2}$ & 1 & 0.52 & 0.4900 & 4.53 & 0.0660 & 9.40 & $0.0155^{*}$ & 24.23 & $0.0012^{*}$ \\
\hline$C^{2}$ & 1 & 4.63 & 0.0635 & 2.49 & 0.1532 & 5.30 & 0.0503 & 0.36 & 0.5625 \\
\hline Lack of Fit & 3 & 0.85 & 0.5252 & 0.031 & 0.9919 & 3.58 & 0.1018 & 2.22 & 0.2036 \\
\hline R-Squared & & 0.9578 & & 0.9790 & & 0.8525 & & 0.9865 & \\
\hline $\begin{array}{c}\text { Adj } \\
\text { R-Squared }\end{array}$ & & 0.9102 & & 0.9554 & & 0.6866 & & 0.9713 & \\
\hline $\begin{array}{c}\text { Pred } \\
\text { R-Squared }\end{array}$ & & 0.7321 & & 0.9642 & & -0.6775 & & 0.8683 & \\
\hline
\end{tabular}

Values of "Prob > F" less than 0.05 indicate significant model terms denoted by * Lack of fit is insignificant for all responses.

\section{Equations}

HPLC Area $=2542450+662623 * \mathrm{~A}-353449 * \mathrm{~B}+$ $53041.5 * \mathrm{C}+44671.8 * \mathrm{AB}+46318.5 * \mathrm{AC}-139034 *$ $\mathrm{BC}+263880 * \mathrm{~A}^{2}+57786.6 * \mathrm{~B}^{2}-171940 * \mathrm{C}^{2}$.

USP $(\mathbf{N T P})=4097.5-649.625 * \mathrm{~A}-774.625 * \mathrm{~B}-31.25$ *C $-74.75 * \mathrm{AB}+70$ * $\mathrm{AC}-62.5 * \mathrm{BC}-294.625 * \mathrm{~A}^{2}+$ $155.875 * \mathrm{~B}^{2}+115.625 * \mathrm{C}^{2}$.

Tailing $=1.062+0.045375 * \mathrm{~A}+0.021125 * \mathrm{~B}+$ $0.01425 * \mathrm{C}-0.0225 * \mathrm{AB}+0.00325 * \mathrm{AC}-0.07625 *$ $\mathrm{BC}+0.03225 * \mathrm{~A}^{2}-0.05925 * \mathrm{~B}^{2}-0.0445 * \mathrm{C}^{2}$.

R.T. $=3.2165+0.061625 * \mathrm{~A}-0.631625 * \mathrm{~B}+0.01975 *$ $\mathrm{C}+0.0295 * \mathrm{AB}-0.00075 * \mathrm{AC}-0.05875 * \mathrm{BC}-0.00225$ $* \mathrm{~A}^{2}+0.17925 * \mathrm{~B}^{2}-0.022 * \mathrm{C}^{2}$.

\section{Linearity}

Method validation was done as per ICH Q2R1 after method development. Change in concentration showed up a linear relation with HPLC area when plotted. The $R^{2}$ value was found to be 1 with high correlation as given in Figure 2 and Table 3. The LOD of $0.08 \mathrm{ppm}$ and LOQ value of $0.25 \mathrm{ppm}$ show that the method is sensitive enough for lower concentrations.

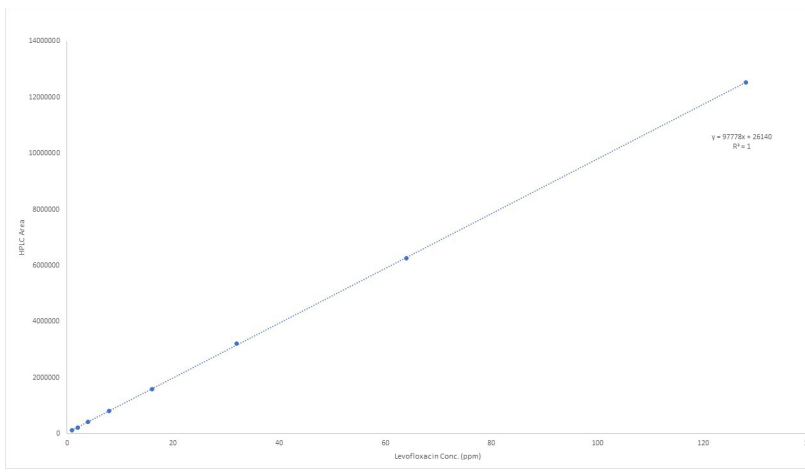

Figure 2: Linearity plot for levofloxacin.

\section{System suitability}

System suitability was run soon after establishing the linearity of the method at $64 \mathrm{ppm} . \%$ RSD value was less than 0.5 with high theoretical plate count $(>20000)$ and tailing factor less than 1.5 as given in Table 3 and exhibited in Figure 3.

\section{Precision}

Method precision and intermediate precision \% RSD values lie between 0.2 and 0.6 which infer good precision of the method. 
Table 3: Linearity, LOD and LOQ, System suitability, Precision.

\begin{tabular}{|c|c|c|c|c|c|c|c|c|}
\hline \multirow{2}{*}{ LOD and LOQ } & \multicolumn{3}{c|}{ Linearity } & \multicolumn{2}{c|}{$\begin{array}{c}\text { System suitability (n=6 } \\
\text { injections) }\end{array}$} & \multicolumn{2}{c|}{$\begin{array}{c}\text { Method precision (n=6 } \\
\text { injections) }\end{array}$} & $\begin{array}{c}\text { Intermediate } \\
\text { precision } \\
\text { (n=6 } \\
\text { injections) }\end{array}$ \\
\hline Correlation & $\mathbf{0 . 9 9 9 2}$ & Correlation & $\mathbf{0 . 9 9 9 9}$ & Average & $\mathbf{6 1 8 8 1 7 7}$ & Average & $\mathbf{6 2 5 9 0 8 0}$ & $\mathbf{6 2 6 2 0 1 2}$ \\
\hline$R^{2}$ & 0.9986 & $R^{2}$ & 1 & SD & \pm 20056 & SD & \pm 17900 & \pm 36013.88 \\
\hline LOD & $0.08 \mathrm{ppm}$ & & & NTP & $>23000$ & Maximum & 6276114 & 6299832 \\
\hline LOQ & $0.25 \mathrm{ppm}$ & & & Tailing factor & $<0.93$ & Minimum & 6230032 & 6203917 \\
\hline
\end{tabular}

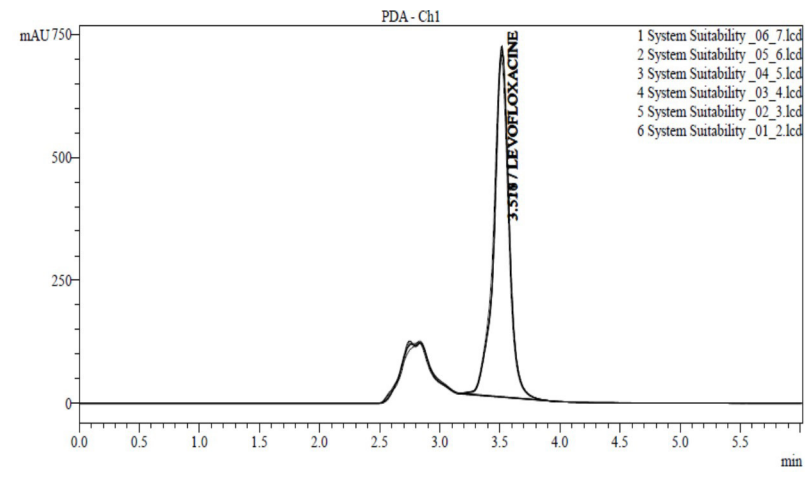

Figure 3: Chromatogram for system suitability.

\section{Accuracy and Recovery}

Accuracy and recovery studies were run at 3 levels. The percent recovery ranged from 99.8-101.6 with \% RSD values $<0.5$. High recovery results indicate that the method can be used for quantitative quality control (QC) studies for various samples.

\section{Robustness}

The robustness study with deliberate variations in the chromatographic conditions had \% RSD values <2, which prove the robustness of the developed method (Table 4).

\section{Solution stability}

Solution stability studies for sample were carried out at two conditions room temperature $\left(25^{\circ} \mathrm{C}\right)$ and refrigeration $\left(2-8^{\circ} \mathrm{C}\right)$ show that the sample prepared in diluent remained stable at both the conditions for $24 \mathrm{hrs}$ as shown in Table 5 .

\section{Peak purity}

Peak purity was established at $32 \mathrm{ppm}$ concentration. Purity index was found to be 0.978 at a threshold value of 1 , where purity index was less than threshold. So, we can conclude that the peak is pure as shown in Figure 4.

\section{Application:SampleAnalysisforPharmacokinetics Study}

Linear calibration curves were plotted for spiked plasma samples at a range of $0.5 \mathrm{ppm}$ to $512 \mathrm{ppm}$. The concentration range was kept low to accommodate the range of expected plasma concentrations. The assay demonstrated good linearity in the selected range with a $R^{2}$ value nearing 0.999 . The specificity studies for plasma samples were done after analysing overplayed chromatograms of spiked and blank samples for absence of interfering peaks at the RT of LH. Chromatograms of test, spiked and blank samples are given in Figure 5(A-C).

\section{Application: Sample Analysis of Nano Formulations for LH Content Estimation}

Nanoformulations containing LH in lipid and PLGA polymer poses problems of drug extraction by simple liquid-liquid extraction where diluents or organic solvents are utilised to extract the drug out of the polymeric shell. The prepared formulations being insoluble in water were difficult to characterise. Upon dissolution in acetonitrile or methanol, they gave an appearance of a homogenous solution to the eye, but during content measurements the drug contents remained much lower than expected. The problem was solved by using alkaline SDS solution to degrade the PLGA polymer chains and enable solubilisation of lipid. This process releases the LH in solution. The samples were further precipitated with diluent to extract out the free drug by centrifugation. The resultant solution so obtained is filtered and diluted to estimate drug content by HPLC. The presence of alkali and SDS in solution leads to change in $\mathrm{pH}$ during measurements which are controlled by making an acidic mobile phase which restricts movement of RT. The specificity of the method was analysed by running parallel samples of placebo, test and standard samples as given in Figure 5 (D-F). The absence of interfering peak at the RT of LH and no significant change in RT can be seen clearly in the representative chromatograms. Marketed tablet 


\begin{tabular}{|c|c|c|c|c|c|c|c|c|c|}
\hline Strength & \multicolumn{2}{|c|}{$\begin{array}{l}\text { Average area } \\
\quad(n=4)\end{array}$} & \multicolumn{2}{|c|}{$\begin{array}{l}\text { Amount } \\
\text { recovered }\end{array}$} & \multicolumn{2}{|c|}{$\%$ Recovery } & Average & \multicolumn{2}{|l|}{ SD } \\
\hline \multirow[t]{4}{*}{$32(50 \%)$} & \multicolumn{2}{|c|}{3176431} & \multicolumn{2}{|c|}{32.21881} & \multicolumn{2}{|c|}{100.6838} & & & \\
\hline & \multicolumn{2}{|c|}{3204916} & \multicolumn{2}{|c|}{32.51014} & \multicolumn{2}{|c|}{101.5942} & & & \\
\hline & \multicolumn{2}{|c|}{3196614} & \multicolumn{2}{|c|}{32.42523} & \multicolumn{2}{|c|}{101.3288} & & & \\
\hline & \multicolumn{2}{|c|}{3179636} & \multicolumn{2}{|c|}{32.25159} & \multicolumn{2}{|c|}{100.7862} & 3189399 & \multicolumn{2}{|l|}{13617.62} \\
\hline \multirow[t]{4}{*}{$64(100 \%)$} & \multicolumn{2}{|c|}{6292802} & \multicolumn{2}{|c|}{64.09072} & \multicolumn{2}{|c|}{100.1417} & & & \\
\hline & \multicolumn{2}{|c|}{6273758} & \multicolumn{2}{|c|}{63.89595} & \multicolumn{2}{|c|}{99.83742} & & & \\
\hline & \multicolumn{2}{|c|}{6316568} & \multicolumn{2}{|c|}{64.33378} & \multicolumn{2}{|c|}{100.5215} & & & \\
\hline & \multicolumn{2}{|c|}{6279722} & $63 . c$ & & & & 6290713 & 18983.49 & 0.30 \\
\hline $96(150 \%)$ & 941 & 814 & 96.0 & & & & & & \\
\hline & 949 & 665 & 96.8 & & & & & & \\
\hline & 944 & 183 & 96.2 & & & & & & \\
\hline & 949 & 824 & 96.8 & & & & 9462372 & 38965.32 & 0.41 \\
\hline & & & & & Robu & & & & \\
\hline Condi & & Avera & Area & & very & \%RSD & RT & USP (NTP) & Tailing factor \\
\hline Column oven te & ture 25 & 610 & & & & 1.29 & 3.557 & 5494.5 & 1.05 \\
\hline Column oven te & ture 30 & 622 & & & & 0.94 & 3.527 & 4855.5 & 0.96 \\
\hline Column oven te & ture 35 & 621 & & & & 0.11 & 3.526 & 4484 & 0.97 \\
\hline Flow rat & & 635 & & & & 0.11 & 3.926 & 4424 & 0.91 \\
\hline Flow rat & & 622 & & & & 0.94 & 3.527 & 4855.5 & 0.96 \\
\hline Flow rat & & 617 & & & & 0.002 & 3.357 & 4658 & 0.95 \\
\hline $\begin{array}{r}\text { Mobile phase } \\
33 \%\end{array}$ & sition & 626 & & & & 1.25 & 3.56 & 4545.5 & 1.20 \\
\hline $\begin{array}{r}\text { Mobile phase } \\
35 \%\end{array}$ & sition & 622 & & & & 0.94 & 3.527 & 4855.5 & 0.96 \\
\hline $\begin{array}{r}\text { Mobile phase } \\
37 \%\end{array}$ & sition & 617 & & & & 1.59 & 3.534 & 6789.5 & 0.94 \\
\hline Waveleng & & 622 & & & & 0.93 & 3.527 & 4861 & 0.98 \\
\hline Waveleng & & 622 & & & & 0.94 & 3.527 & 4855.5 & 0.96 \\
\hline Waveleng & & 614 & & & & 0.94 & 3.527 & 4854.5 & 0.98 \\
\hline
\end{tabular}

\begin{tabular}{|c|c|c|}
\hline \multicolumn{3}{|c|}{ Table 5: Solution stability. } \\
\hline Time in hr & $\begin{array}{c}\text { HPLC Area } \\
(\boldsymbol{n}=\mathbf{3})\end{array}$ & \% Absolute difference \\
\hline Initial & 6411310 & 0 \\
\hline $4 \mathrm{hr}$ Room Temp & 6411310 & 0 \\
\hline 4 hr Refrigeration & 6411250 & 0.000935846 \\
\hline 12 hr Room Temp & 6411598 & 0.004492062 \\
\hline 12 hr Refrigeration & 6411985 & 0.01052827 \\
\hline $24 \mathrm{hr}$ Room Temp & 6411250 & 0.000935846 \\
\hline $24 \mathrm{hr}$ Refrigeration & 6411480 & 0.002651564 \\
\hline
\end{tabular}

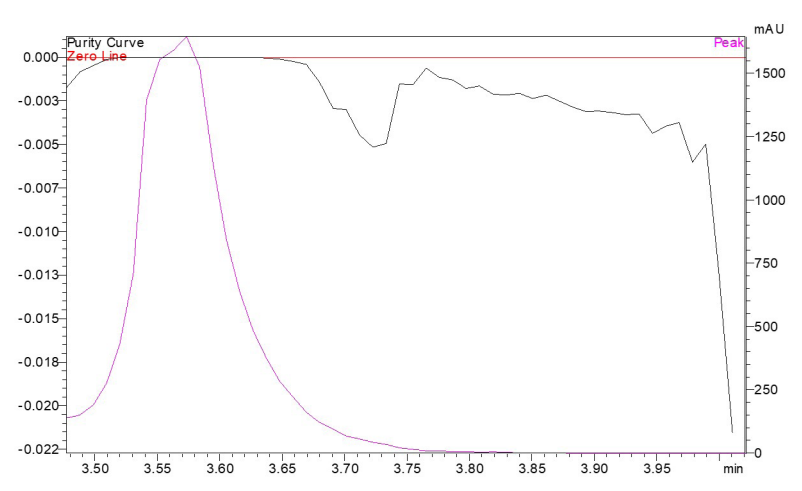

Figure 4: Peak purity profile. 


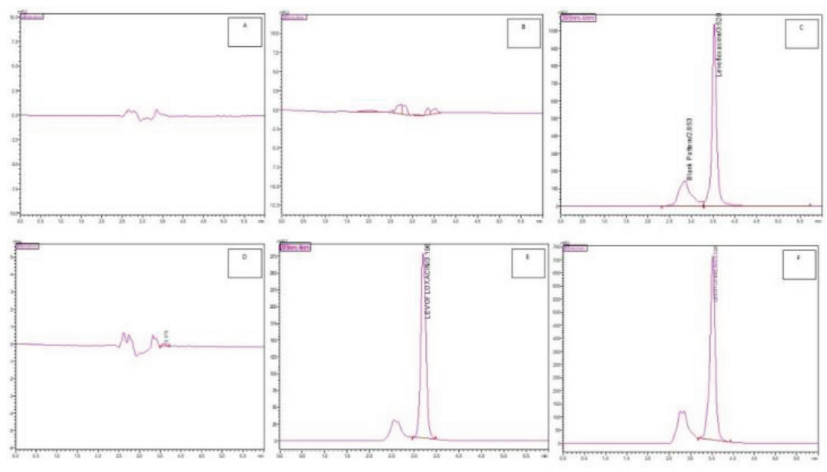

Figure 5: Specificity study A: Blank sample, B: Placebo plasma. C: Plasma sample, D: Placebo nanoformulation, E: Marketed, F: Nanoformulation.

Levaquin was used as a standard for $\mathrm{LH}$ estimation in nanoformulations. Standard I.P. assay procedure was used to prepare the samples.

\section{CONCLUSION}

The developed RP-HPLC method was quiet efficient in estimating LH content in nanoformulations, plasma samples and marketed conventional formulations with fast RT, resolution and sufficient specificity. The RP-HPLC method was entirely validated as per ICH Q2R1 guidelines. Since the method requires a short run time it can easily assess several samples in a short span of time. The method is robust, selective and simple with increased sensitivity for $\mathrm{LH}$ estimation. BBD used in development of method allowed better identification of significant factors affecting resolution. Until now there has been no novel method for estimation of $\mathrm{LH}$ in nanoformulations as well as in plasma samples for pharmacokinetic studies.

\section{ACKNOWLEDGEMENT}

Authors are extremely grateful to Vice chancellor BBAU for providing constant support and necessary facilities. Authors would like to thank CDRI, Lucknow for extending their lab facilities. This is CSIR-CDRI communication 10272.

\section{CONFLICT OF INTEREST}

The authors declare that they have no known competing financial or personal interests that can influence the work reported in this paper.

\section{ABBREVIATIONS}

ANOVA: Analysis of variance; BBD: Box Behnken Design; BCS: Biopharmaceutical Classification System;
LH: Levofloxacin hemihydrate; LOD: Limit of detection; LOQ: Limit of quantification; NTP: Number of theoretical plates; PLGA: Poly D,L-lactic-co-glycolic acid; PPM: Parts per million; QC: Quality control; RP-HPLC: Reversed phase-High performance liquid chromatography; RSD: Relative standard deviation; RT: Retention time.

\section{REFERENCES}

1. Dabhi B, Parmar B, Patel N, Jadeja Y, Patel M, Jebaliya H, Karia D, Shah AK. A stability indicating UPLC method for the determination of levofloxacin hemihydrate in pharmaceutical dosage form: application to pharmaceutical analysis. Chromatogr Res Int. 2013;2013:1-5. doi: 10.1155/2013/432753.

2. Lalitha Devi $M$, Chandrasekhar KB. A validated stability-indicating RP-HPLC method for levofloxacin in the presence of degradation products, its process related impurities and identification of oxidative degradant. J Pharm Biomed Anal. 2009 Dec;50(5):710-7. doi: 10.1016/j.jpba.2009.05.038, PMID 19632800.

3. Gupta H, Aqil M, Khar RK, Ali A, Chander P. A single reversed-phase UPLC method for quantification of levofloxacin in aqueous humour and pharmaceutical dosage forms. J Chromatogr Sci. 2010 Jul;48(6):484-90. doi: 10.1093/chromsci/48.6.484, PMID 20822665.

4. Costa A, Pinheiro M, Magalhães J, Ribeiro R, Seabra V, Reis S, Sarmento B. The formulation of nanomedicines for treating tuberculosis. Adv Drug Deliv Rev. 2016 Jul 1;102:102-15. doi: 10.1016/j.addr.2016.04.012, PMID 27108703.

5. Raizman MB, Rubin JM, Graves AL, Rinehart M. Tear concentrations of levofloxacin following topical administration of a single dose of $0.5 \%$ levofloxacin ophthalmic solution in healthy volunteers. Clin Ther. 2002 Sep;24(9):1439-50. doi: 10.1016/s0149-2918(02)80047-9, PMID 12380635.

6. Koeppe MO, Cristofoletti R, Fernandes EF, Storpirtis S, Junginger HE, Kopp S, Midha KK, Shah VP, Stavchansky S, Dressman JB, Barends DM. Biowaiver monographs for immediate release solid oral dosage forms: levofloxacin. J Pharm Sci. 2011;100(5):1628-36. doi: 10.1002/jps.22413, PMID 21374601.

7. Bao D, Truong T-TT, Renick PJ, Pulse ME, Weiss WJ. Simultaneous determination of rifampicin and levofloxacin concentrations in catheter segments from a mouse model of a device-related infection by liquid chromatography/electrospray ionization tandem mass spectrometry. J Pharm Biomed Anal. 2008 Mar;46(4):723-7. doi: 10.1016/j.jpba.2007.11.023, PMID 18178051.

8. Van TP, Pouplin T, Duc N, Tho K, Nguyen P, Thi T, et al. High-performance liquid chromatography with time-programmed fluorescence detection for the quantifi cation of Levofloxacin in human plasma and cerebrospinal fl uid in adults with tuberculous meningitis. J Chromatogr B. 2017;10611062(Jul):256-62.

9. Alwera S, Bhushan R. RP-HPLC enantioseparation of $\beta$-adrenolytics using micellar mobile phase without organic solvents. Biomed Chromatogr. 2017 Nov;31(11). doi: 10.1002/bmc.3983, PMID 28370275.

10. Lee SJ, Desta KT, Eum SY, Dartois V, Cho SN, Bae DW, Shin SC. Development and validation of LC-ESI-MS/MS method for analysis of moxifloxacin and levofloxacin in serum of multidrug-resistant tuberculosis patients: potential application as therapeutic drug monitoring tool in medical diagnosis. J Chromatogr B Analyt Technol Biomed Life Sci. 2016;10091010:138-43. doi: 10.1016/j.jchromb.2015.11.058, PMID 26730550.

11. Rey-Jurado E, Tudó G, Soy D, González-Martín J. Activity and interactions of levofloxacin, linezolid, ethambutol and amikacin in three-drug combinations against Mycobacterium tuberculosis isolates in a human macrophage model. Int J Antimicrob Agents. 2013;42(6):524-30. doi: 10.1016/j. ijantimicag.2013.07.014, PMID 24080479.

12. Naveed S, Sultana N, Arayne MS, Dilshad H. A new HPLC method for the assay of levofloxacin and its application in drug-metal interaction studies. J Sci Innov Res. 2014;3(1):91-6. 
13. Lourenço MCS, Junior IN, De Souza MVN. In vitro activity of ciprofloxacin, ofloxacin, levofloxacin, sparfloxacin and gatifloxacin against multidrugresistant Mycobacterium tuberculosis in Rio de Janeiro Brazil. Med Mal Infect. 2007;37(5):295-6. doi: 10.1016/j.medmal.2007.03.011, PMID 17459633.

14. Dafale NA, Semwal UP, Agarwal PK, Sharma P, Singh GN. Development and validation of microbial bioassay for quantification of levofloxacin in pharmaceutical preparations. J Pharm Anal. 2015 Feb;5(1):18-26. doi: 10.1016/j.jpha.2014.07.007, PMID 29403911.

15. Shahwal V, Dubey BK, Bhoumick M. Preformulation study of levofloxacin. Int J Adv Pharm. 2012;1(1):225-7.

16. Salem AA, Mossa HA. Method validation and determinations of levofloxacin, metronidazole and sulfamethoxazole in an aqueous pharmaceutical, urine and blood plasma samples using quantitative nuclear magnetic resonance spectrometry. Talanta. 2012;88:104-14. doi: 10.1016/j.talanta.2011.10.016, PMID 22265475.

17. Böttcher S, von Baum HV, Hoppe-Tichy T, Benz C, Sonntag HG. An HPLC assay and a microbiological assay to determine levofloxacin in soft tissue, bone, bile and serum. J Pharm Biomed Anal. 2001;25(2):197-203. doi: 10.1016/s0731-7085(00)00478-7, PMID 11275428

18. Dey B, Mahapatra S, Tiwari P. Formulation and analysis of levofloxacin hemihydrate by RP-HPLC in bulk and tablet dosage form. J Harmonized Res (JOHR). 2014;3(2):64-77.

19. Prideaux B, EINaggar MS, Zimmerman M, Wiseman JM, Li X, Dartois V. Mass spectrometry imaging of levofloxacin distribution in TB-infected pulmonary lesions by MALDI-MSI and continuous liquid microjunction surface sampling. Int J Mass Spectrom. 2015;377:699-708. doi: 10.1016/j.jjms.2014.08.024, PMID 26185484.

20. Szerkus O, Jacyna J, Gibas A, Sieczkowski M, Siluk D, Matuszewski M, Kaliszan R, Markuszewski MJ. Robust HPLC-MS/MS method for levofloxacin and ciprofloxacin determination in human prostate tissue. J Pharm Biomed Anal. 2017 Jan;132:173-83. doi: 10.1016/j.jpba.2016.10.008, PMID 27744176.

21. Siewert S. Validation of a levofloxacin HPLC assay in plasma and dialysate for pharmacokinetic studies. J Pharm Biomed Anal. 2006 Jun;41(4):1360-2. doi: 10.1016/j.jpba.2006.02.010, PMID 16563690.

22. Arayne MS, Sultana N, Siddiqui FA. Optimization of levofloxacin analysis by RP-HPLC using multivariate calibration technique. Pak J Pharm Sci. 2007 Apr;20(2):100-6. PMID 17416562.

23. Patel SA, Prajapati AM, Patel PU, Patel NJ, Vaghmasi JB. Development and validation of column high-performance liquid chromatographic and derivative spectrophotometric methods for determination of levofloxacin and ornidazole in combined dosage forms. J AOAC Int. 2008;91(4):756-61. doi: 10.1093/ jaoac/91.4.756, PMID 18727534.

24. Luo S, Lei J, Zhang R, Cai H, Li R. [Determination of levofloxacin in plasma and cerebrospinal fluid with HPLC and its pharmacokinetics in patients undergoing neurosurgical operations]. Yao xue xue bao Acta pharm Sin. 1998 Dec;33(12):937-40. PMID 12016861.

25. Schulte S, Ackermann T, Bertram N, Sauerbruch T, Paar WD. Determination of the newer quinolones levofloxacin and moxifloxacin in plasma by high-performance liquid chromatography with fluorescence detection. J Chromatogr Sci. 2006 Apr;44(4):205-8. doi: 10.1093/chromsci/44.4.205, PMID 16620519.

26. Tobin CM, Sunderland J, White LO, MacGowan AP. A reverse-phase, isocratic high-performance liquid chromatography assay for levofloxacin. $J$
Antimicrob Chemother. 1999;43(3):434-5. doi: 10.1093/jac/43.3.434, PMID 10223609.

27. Bhalerao H, Koteshwara KB, Chandran S. Levofloxacin hemihydrate in situ gelling ophthalmic solution: formulation optimization and in vitro and in vivo evaluation. AAPS PharmSciTech. 2019;20(7):272. doi: 10.1208/s12249-0191489-6, PMID 31372767.

28. Gupta PV, Nirwane AM, Nagarsenker MS. Inhalable levofloxacin liposomes complemented with lysozyme for treatment of pulmonary infection in rats: effective antimicrobial and antibiofilm strategy. AAPS PharmSciTech. 2018;19(3):1454-67. doi: 10.1208/s12249-017-0945-4, PMID 29464594.

29. Salama HA, Ghorab M, Mahmoud AA, Abdel Hady M. PLGA nanoparticles as subconjunctival injection for management of glaucoma. AAPS PharmSciTech. 2017;18(7):2517-28. doi: 10.1208/s12249-017-0710-8, PMID 28224390.

30. Czyrski A, Sznura J. The application of Box-Behnken-Design in the optimization of HPLC separation of fluoroquinolones. Sci Rep. 2019;9(1):19458. doi: 10.1038/s41598-019-55761-z, PMID 31857613.

31. Szerkus O, Jacyna J, Wiczling P, Gibas A, Sieczkowski M, Siluk D, Matuszewski M, Kaliszan R, Markuszewski MJ. Ultra-high performance liquid chromatographic determination of levofloxacin in human plasma and prostate tissue with use of experimental design optimization procedures. J Chromatogr B Analyt Technol Biomed Life Sci. 2016;1029-1030:48-59. doi: 10.1016/j.jchromb.2016.06.051, PMID 27423043.

32. Garg NK, Sharma G, Singh B, Nirbhavane P, Katare OP. Quality by design $(\mathrm{QbD})$-based development and optimization of a simple, robust RP-HPLC method for the estimation of methotrexate. J Liq Chromatogr Relat Technol. 2015;38(17):1629-37. doi: 10.1080/10826076.2015.1087409.

33. Trivedi RN, Shah PA, Thakkar VT. Implementation of Box-Behnken experimental design for the robustness study and its comprehensive approach in development and validation of RP-HPLC method for simultaneous estimation of rifampicin and levofloxacin; 2017.

34. Aşçi B, Dinç Zor Ş, Aksu Dönmez Ö. Development and validation of HPLC method for the simultaneous determination of five food additives and caffeine in soft drinks. Int J Anal Chem. 2016;2016:2879406. doi: 10.1155/2016/2879406, PMID 26989415.

35. Suryawanshi D, Jha DK, Shinde U, Amin PD. Development and validation of a stability-indicating RP-HPLC method of cholecalciferol in bulk and pharmaceutical formulations: analytical quality by design approach. J App Pharm Sci. 2019;9(6):21-32. doi: 10.7324/JAPS.2019.90604.

36. Fukuda IM, Pinto CFF, Moreira CdS, Saviano AM, Lourenço FR. Design of experiments (DoE) applied to pharmaceutical and analytical quality by design (QbD). Braz J Pharm Sci. 2018;54(spe);Special Issue:1-16. doi: 10.1590/ s2175-97902018000001006.

37. Varghese SE, Fariya MK, Rajawat GS, Steiniger F, Fahr A, Nagarsenker MS. Lecithin and PLGA-based self-assembled nanocomposite, Lecithmer: preparation, characterization, and pharmacokinetic/pharmacodynamic evaluation. Drug Deliv TransI Res. 2016;6(4):342-53. doi: 10.1007/s13346016-0314-y, PMID 27371394. 
PICTORIAL ABSTRACT

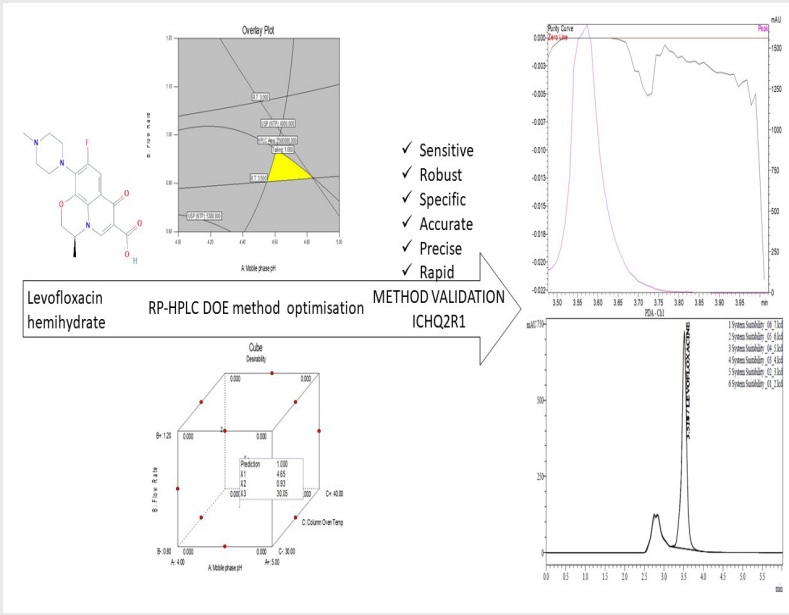

\section{SUMMARY}

A robust, rapid, simple, selective, sensitive RP-HPLC analytical method was developed and validated as per ICH Q2R1.Levofloxacin was extracted from plasma by liquid-liquid extraction and was measured using a validated RP-HPLC method with UV detector set at $295 \mathrm{~nm}$. The DOE optimised developed method can be used for rapid estimation of levofloxacin in nanoformulations, marketed formulations and plasma samples without shift in RT. The significant reduction in retention time obtained by the developed method proves its efficiency in tapping the mobile phase costs as well as expediting the analytical process. Development of analytical method that uses minimal solvents with least preparation time also helps in reducing the errors.

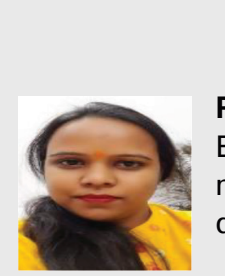

\begin{abstract}
About Authors
Priyanka Maurya is presently pursuing her doctoral degree at the School of Pharmaceutical Sciences, BBAU, Lucknow. She has research experience of 8 years. Her research work encompasses alveolar macrophage targeted hybrid nano-systems, nanocrystals for solubility enhancement, bioadhesive drug delivery systems and biomaterials.
\end{abstract}

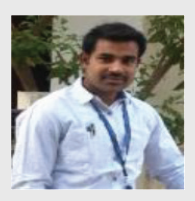

Abhiram Kumar has 6 years of research experience in reputed pharmaceutical R\&D and in CSIR-CDRI. His area of interest is analytical research and development, separation techniques, pharmacokinetics, preclinical studies, proteomics and metabolomics.

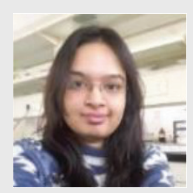

Samipta Singh is a research scholar at BBAU, Lucknow. She has five years of research experience; presently, she is working on targeted nanoformulations against breast cancer. She has received DST-AWSAR award in 2019 for her research story. She is a proud recipient of ICMR-SRF-2020.

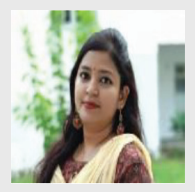

Raquibun Nisha is pursuing her doctoral degree at BBAU Lucknow. She is presently working on nanoformulations against hepatocellular carcinoma. She has two research papers to her credit. She has qualified GPAT 2017 and is a recipient of ICMR-SRF-2020.

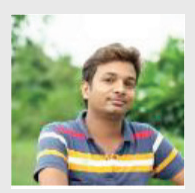

Ravi Raj Pal is an associate member of the Institution of Chemists, Kolkata, since January 2020. $\mathrm{He}$ is a Doctoral student at the School of Pharmaceutical Sciences. His research areas include nanoformulations for the treatment of atopic dermatitis. He has qualified GPAT 2017 and is a recipient of ICMR-SRF-2020. 

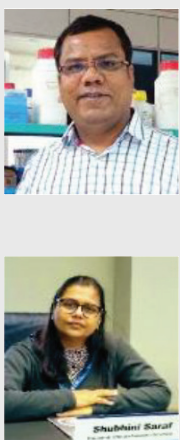

Dr. Manish K Chourasia is a senior scientist in the Pharmaceutics division at CSIR-CDRI. His research interests include the development and characterization (in-vitro and in-vivo) of novel drug delivery systems, including nanoparticles, nanoemulsion, micellar systems, nanocrystals, and liposomes. Cell culture-based assays, fluorescence microscopy, flow cytometry \& the Pre-clinical drug development program.

Prof. Shubhini A Saraf is Dean, School of Pharmaceutical Sciences. Additionally, she is the Dean, Research and Development, BBAU. Her research interests include Lipidic drug delivery systems, formulations in cancer research. Her research group aims at understanding nanotechnology through material science research, principles of green nanotechnology, drug targeting approaches and various techniques of in vitro and in vivo evaluation.

Cite this article: Maurya P, Kumar A, Singh S, Nisha R, Pal RR, Chourasia MK, Saraf SA. Bio-Analytical Method Development for Estimation of Levofloxacin: Application in Estimation of Drug in Nano-formulations and Pharmacokinetic Studies. Indian J of Pharmaceutical Education and Research. 2021;55(3s):s814-s824. 